\title{
FAROL DO SABER: LIMITES E POSSIBILIDADES DE UMA BIBLIOTECA ESCOLAR NA FORMAÇÃO DE LEITORES LITERÁRIOS
}

\author{
Elisa MARIA DALLA-BONA \\ Charlene da Silva Andrade de Lima \\ Universidade Federal do Paraná (UFPR), Curitiba, Paraná, Brasil
}

Resumo: Neste estudo de caso de natureza etnográfica, desenvolvido em 2015, investigam-se as ações desenvolvidas num Farol do Saber, da Rede Municipal de Bibliotecas Escolares de Curitiba. As especificidades de uma biblioteca escolar, segundo diversos autores, incluem: função educativa e integração à escola; espaço de convivência, de debate, de reflexão e de incentivo à leitura; acervo de qualidade, direcionado para jovens leitores e com acesso integral e livre aos alunos e professores; ambiente de liberdade e ludicidade; mediadores de leitura com ações planejadas para a interação entre as pessoas e as obras; e fomento de leitores autônomos, capazes de buscar o que desejam no acervo e de refletir sobre a leitura realizada. Conclui-se que o Farol do Saber pesquisado cumpre a função de biblioteca escolar de forma limitada e precisa ser repensado para de fato formar leitores.

PalavRAS-Chave: Biblioteca escolar. Mediação de leitura. Formação de leitores. Literatura infantil.

1 INTRODUÇÃO

A biblioteca escolar é segundo a UNESCO e a IFLA (2009, p. 2) "parte integral do processo educativo", trata-se de um espaço que tem uma 
tarefa político-pedagógica de suma importância na formação do leitor. No entanto, os dados do Censo Escolar 2013 apontam para as deficiências destes equipamentos, no Brasil há $65 \%$ de escolas públicas e privadas sem bibliotecas e no Paraná este percentual é de $42 \%$. O município de Curitiba apresenta um quadro bem melhor equacionado que a situação brasileira, contando com $96,7 \%$ das escolas municipais com biblioteca.

A Secretaria Municipal de Educação de Curitiba possui uma Rede Municipal de Bibliotecas Escolares (RMBE), atualmente com 193 unidades, sendo 178 bibliotecas escolares (146 bibliotecas em escolas e 32 faróis do saber anexos às escolas); 9 faróis do saber em praças; 3 bibliotecas temáticas; 1 biblioteca especializada em educação e 2 gibitecas.

Os faróis do saber são bibliotecas dos bairros da cidade de Curitiba e, em geral, são integrados às escolas municipais, atendendo aos alunos, professores e à comunidade. Eles foram criados na década de 1990 inspirados na primeira biblioteca do mundo, localizada na velha Alexandria (Egito) e situada junto ao Farol de Alexandria. Conforme demonstrado na Figura 1, a arquitetura destas bibliotecas é diferenciada.

Figura 1 - Farol do Saber em Curitiba.

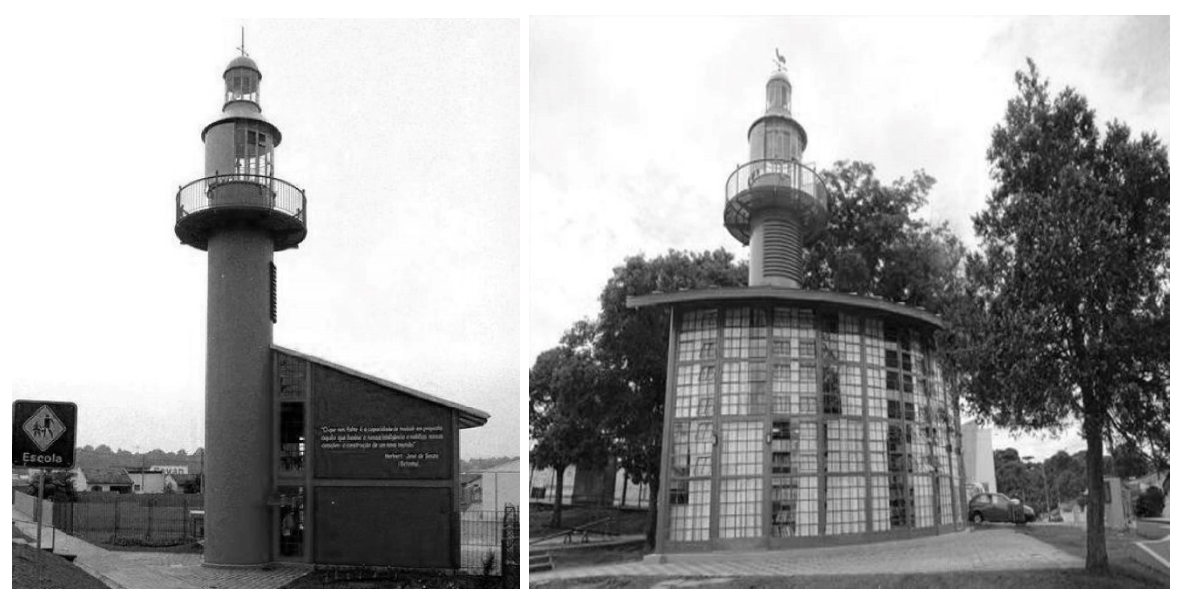

Fonte: Fotos da página da Rede Municipal de Bibliotecas Escolares de Curitiba (2015).

Os faróis do saber têm $88 \mathrm{~m}^{2}$ de área e dois pavimentos, sendo que o térreo abriga o acervo literário (Figura 2) e no piso superior estão os computadores para pesquisa e acesso à internet (Figura 2), onde são realizadas as atividades de leitura e contação de histórias. 
Figura 2 - Imagem do piso inferior e superior do Farol do Saber.

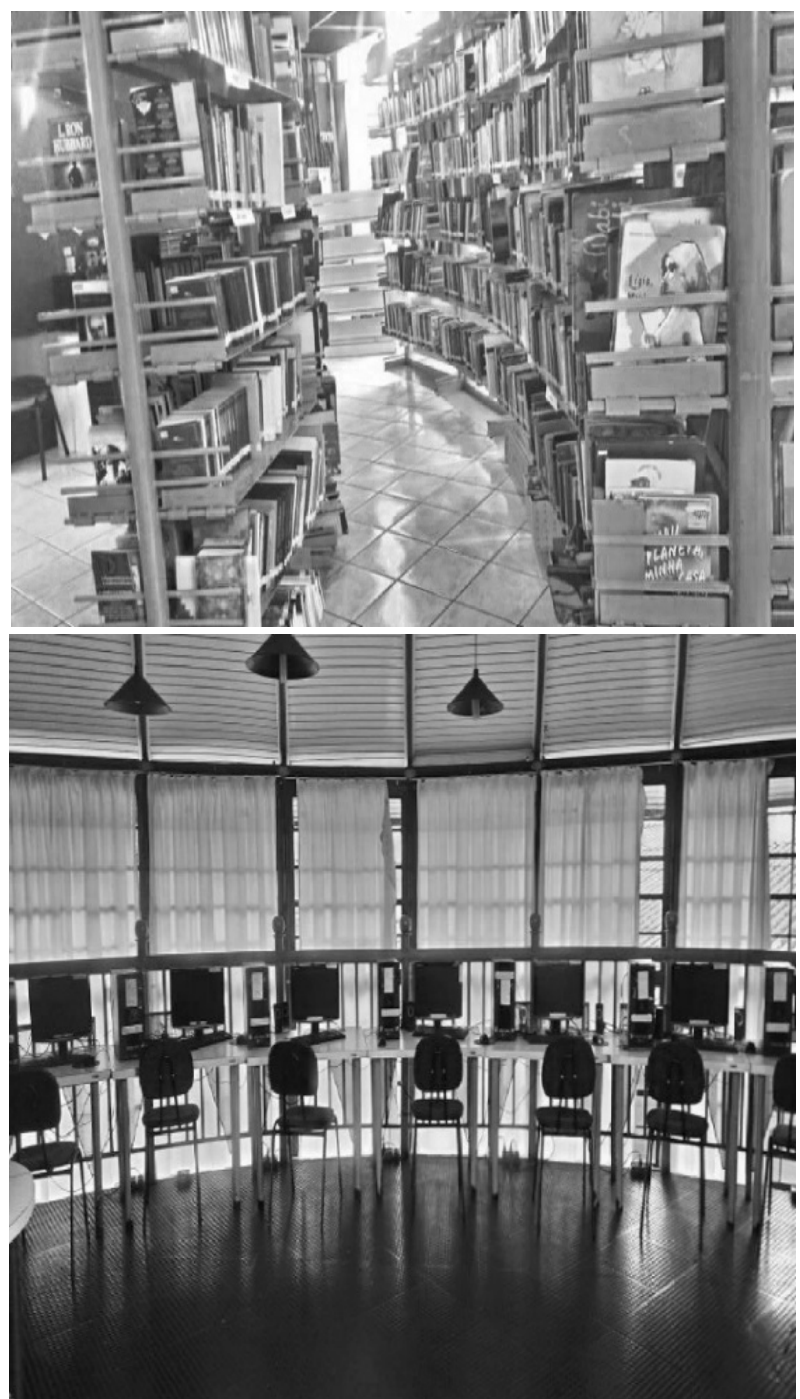

Fonte: Foto elaborada por uma das pesquisadoras (2015).

Cabe destacar que, no âmbito da RMBE, os faróis do saber são entendidos como ambientes pedagógicos e são integrados às escolas, sendo um espaço para mediação da leitura, pesquisas e difusão cultural. 


\section{A PESQUISA}

No ano de 2015 foi desenvolvida uma pesquisa, no âmbito do Programa de Pós-Graduação: Teoria e Prática de Ensino, da Universidade Federal do Paraná', cujo objetivo foi o de observar as rotinas de um Farol do Saber. Trata-se de um "estudo em profundidade de um fenômeno educacional, com ênfase na sua singularidade e levando em conta os princípios e métodos da etnografia." (ANDRÉ, 2008, p. 19). Este estudo de caso possibilitou realizar uma análise profunda de um objeto de pesquisa, visando o detalhamento de um ambiente (GODOY, 1995) e de seu funcionamento. A partir das observações de um ambiente natural procurou-se conhecer e interpretar a realidade sem nela interferir.

O estudo foi orientado pelas perguntas: como ocorre a formação do leitor no Farol do Saber, ou numa biblioteca escolar? E como são realizadas as mediações de leitura nesse espaço? A pesquisa de campo foi realizada num Farol do Saber anexo a uma escola municipal que atende 438 alunos dos anos iniciais do Ensino Fundamental, na região sul de Curitiba, no bairro do Pinheirinho. Nele trabalham três professoras, que são denominadas agentes de leitura, e um estagiário responsável pelo acesso dos visitantes à área de computadores. Este Farol do Saber segue o calendário e os horários da escola, funcionando das $7 \mathrm{~h} 30$ às $11 \mathrm{~h} 30$ e de $13 \mathrm{~h} 30$ às $17 \mathrm{~h} 30$. Fecha duas horas para o almoço.

É significativo o número de empréstimos realizados por alunos e pela comunidade, só em 2015 totalizaram em torno de 7.000 empréstimos. Naquele ano o acervo deste Farol do Saber contabilizava em torno de 6.000 exemplares, sendo que a maior parte chegou no ano da inauguração (1997). Mas o acervo não estava desatualizado graças ao recebimento permanente de obras enviadas pelo Programa Nacional Biblioteca da Escola - PNBE (em 2015 enviou 450 livros), às compras com os recursos da escola, além de eventuais remessas pela Prefeitura Municipal de Curitiba. Há também doações da comunidade.

As observações de campo aconteceram no período de agosto a dezembro de 2015, em dias alternados, nos horários em que os agentes de leitura recebiam as crianças da escola, perfazendo 44 horas no total. Em tempo real foram registrados, num diário de campo, todos os acontecimentos relativos aos empréstimos de livros, ao uso do espaço físico, e à rotina do trabalho dos agentes de leitura, seus planejamentos, o atendimento aos alunos e as mediações de leitura.

Além das observações também foram realizadas entrevistas que permitiram a integração com os sujeitos da pesquisa, e a análise de 
documentos, como o Caderno Pedagógico da RMBE e orientações da RMBE às unidades.

Foram entrevistadas as agentes de leitura do Farol do Saber e o gerente da RMBE. Os questionamentos às agentes de leitura focaram em aspectos como o planejamento das atividades, as ações de mediação, as rotinas, os empréstimos de livros, a composição dos acervos, a formação continuada dos agentes e a relação do Farol do Saber com a escola. Com o gerente tratou-se sobre a formação dos agentes de leitura e sua designação para as unidades da rede; as especificidades do Farol do Saber; os registros de empréstimos; as orientações das ações de mediações de leitura e planejamentos de mediações nas bibliotecas escolares; a composição dos acervos; e sobre o caderno pedagógico da RMBE. Dada a dificuldade de obter dados sobre o histórico e a inauguração daquele Farol do Saber, isso também foi conversado com as professoras da escola que já estavam lá antes da instalação do Farol do Saber.

Neste sentido, ao longo da pesquisa procurou-se retratar os dados da realidade "já que a finalidade do estudo de caso é retratar uma unidade em ação" (LÜDKE; ANDRÉ, 1986, p. 22), e ao mesmo tempo refletir sobre essas observações, enfim sobre os limites e possibilidades de uma biblioteca escolar na formação de leitores.

\section{As ESPECIFICIDADES DA BIBLIOTECA ESCOLAR}

As características essenciais de uma biblioteca escolar são "a oferta de livros de qualidade, a presença de um adulto atento que lhes dê vida, a liberdade oferecida às crianças" (PATTE, 2012, p. 103). Ela deve propiciar a circulação de livros e situações de leituras que marquem a vida dos alunos, especialmente porque a escola, às vezes, é o único lugar onde eles terão oportunidade de acesso aos livros. A biblioteca quando de fato integrada à dinâmica escolar e voltada para o incentivo à leitura favorece a convivência, a reflexão e o debate (BRASIL, 2008), bem como a autonomia dos seus usuários para que estes consigam de forma independente interagir e circular no espaço para buscar o que desejam e desfrutar do prazer da leitura.

Para Patte (2012), a biblioteca é um elo de convivência, uma necessidade. Ela é um ambiente cultural único e profundamente humano em que os contratos, a diversidade, o encontro, as relações interpessoais e a comunicação são acentuados. De acordo com a autora, para que a criança possa ter uma experiência literária plena, vivida de maneira autêntica, livre, aberta, informal e em movimento, os momentos na biblioteca precisam distinguir-se dos tempos de aprendizagem estritamente escolar de rigidez e de controle. 
Mas, além dos momentos livres, é desejável que os mediadores de leitura planejem as suas ações de forma cooperativa e integrada com os professores, os pedagogos e o diretor. A integração entre a biblioteca e a escola enriquece e potencializa a formação do leitor, pois se percebe, a partir da sequência de encaminhamentos e intenções pedagógicas, um movimento único e direcionado. Uma biblioteca com livros intactos, um lugar de silêncio e passividade, que provoca medo não é um lugar pensado no jovem leitor.

Uma das atividades frequentes nas bibliotecas escolares é a contação de histórias que, segundo Girotto e Souza (2009), muito contribui no processo de formação do leitor, de estímulo à atividade literária, à circulação dos livros, do conhecimento, e também das pessoas. As autoras enfatizam que a hora do conto, o empréstimo de livros, os projetos, as sequências de atividades, a leitura livre, silenciosa e direcionada, os recitais de poesia, as oficinas de criação literária etc. também demandam reflexões e planejamento, sob risco de perderem seu sentido, ou serem muito repetidas e sem diferenciação. A diversificação e a qualidade das atividades são resultantes de um planejamento bem elaborado e com objetivos claros.

Para além das atividades coletivas, aqueles momentos de introspecção da leitura também são indispensáveis. Bortolin e Júnior (2009) ressaltam a importância de se planejarem e assegurarem na biblioteca escolar os momentos de leitura silenciosa em que o contato com o texto ocorra sem a mediação da voz, pois o leitor autônomo é o que consegue construir sozinho sentido para o texto, sem auxílio de outros suportes. Os autores se referem ainda à ludicidade como uma estratégia significativa para atrair os jovens leitores, mas equivocadamente imagina-se que ela está presente nos momentos coletivos. Eles dizem que o ludismo está presente na própria atividade da leitura, desde que o leitor tenha adquirido autonomia, desde que ele seja capaz de ser o contador para si mesmo, não precisando que sempre alguém preencha os espaços com sua voz, com imagens, com representação teatral, com fantoches.

A função do profissional que atua na biblioteca escolar, mais do que emprestar livros ou organizar estantes é a de mediador de leitura. W. C. Silva (2003, p. 77) destaca que "a tarefa de orientar o aluno na utilização da biblioteca e, principalmente, a de despertar nele o gosto e o hábito de leitura são as atribuições mais reveladoras da natureza educativa do trabalho biblioteconômico na escola". Seu ofício não é o de simples distribuidor, o essencial de sua tarefa é a atenção às pessoas que deve vir em primeiro lugar (PATTE, 2012). O gosto pela leitura despertado por "um professor, um bibliotecário que, levado por sua paixão, a transmite através de uma 
relação individual" (PETIT, 2008, p. 166) é marcante e inesquecível para um leitor em formação.

Bortolin e Júnior (2009) sinalizam a necessidade do profissional que atua na biblioteca escolar ser versátil e empático, apresentando em sua atividade e na relação com o aluno uma postura respeitosa, flexível e interessada. Outra característica básica é ser um modelo a ser seguido de leitor. O verdadeiro mediador é um leitor convicto do desejo de compartilhar o melhor, sempre pondo em suas iniciativas a indispensável mediação humana entre as pessoas e as obras.

O mediador de leitura da biblioteca escolar precisa ter consciência de sua função educativa e pedagógica, ter a capacidade de criar, de inovar, coordenar as atividades, bem como ser capaz de ressignificar o ambiente da biblioteca escolar como espaço lúdico e prazeroso em torno da leitura, "para que os alunos, além de se sentirem atraídos, tenham prazer em permanecer nesse ambiente, alterando o conceito da biblioteca escolar que desde o seu primórdio é tida como um local insosso e desagradável." (BORTOLIN; JÚNIOR, 2009, p. 208).

É condição para, de fato, atuar como agente de leitura que o profissional atuando na biblioteca escolar disponibilize os acervos, conheça os livros e transite por entre os conhecimentos literários, o que lhe permitirá apresentar os livros aos alunos, realizar debates, compartilhamentos e conversas sobre os livros e, assim, tornar os alunos mais proficientes em leitura. De acordo com Ferreira (2009, p. 75) "o mediador pode propor para a leitura obras cada vez mais comunicativas que instaurem distâncias estéticas maiores". Ao apresentar textos plurissignificativos e propor a reflexão e o debate ocorrerá a interação tanto com o próprio texto, quanto com outros leitores. (FERREIRA, 2009).

A biblioteca escolar é um local privilegiado, considerando seu espaço e acervo, para fomentar nos alunos o desejo e o encanto pela literatura e pelos livros. Ao disponibilizar os acervos e promover leituras diversas, bem como apreciação dessas obras, o agente de leitura pode incrementar esse trabalho paulatinamente, e aos poucos ir ampliando as estratégias de uso dos acervos. Dessa forma,

O trabalho com a literatura pode ser enriquecido, por exemplo, com a apresentação de autores e ilustradores dos livros que foram lidos, e dos componentes da literatura, como: constância do enredo, caracterização, tema, estilo, lugar, ponto de vista do autor etc. A mobilização desses conhecimentos sobre a qualidade e os critérios singulares de cada tipo de literatura permite o desenvolvimento do que podemos chamar de consciência literária pelas crianças. (SANTOS; SOUZA, 2009, p. 100). 
O gradativo contato do aluno com a literatura de qualidade favorecerá o refinamento da sua sensibilidade e o tornará cada vez mais exigente, mais crítico e consciente, assim, o trabalho do mediador nunca acaba, pois é um processo que demanda tempo e investimento pedagógico. Dessa maneira é necessário diversificar e ampliar suas ações, pois,

Quando os professores bibliotecários nutrem consistentemente o interesse de seus alunos pela literatura, por meio da leitura em voz alta de livros bem selecionados, dando às crianças tempo para que elas possam ler e discutir esses exemplares em grupos, a capacidade delas de apreciação pela qualidade da literatura vai aumentar. Um dos maiores propósitos do programa de literatura deve ser desenvolver a habilidade de leitores críticos. (SANTOS, SOUZA, 2009, p. 101).

Uma das funções do mediador de leitura de uma biblioteca escolar é instigar o aluno a procurar as ideias aglomeradas, as imagens, formas, representações e sinais que são lidos e, nem sempre, percebidos na primeira leitura. Ele pode auxiliar a dar "sentido aos livros e ao mundo revisitado, reinterpretado pela leitura e pelos modos de ler" (ARENA, 2009, p. 162), ajudar o aluno a encontrar no texto as diferentes formas de ler ou direções que podem ir e vir de qualquer lugar (não na sequência linear dos fatos), percebendo a significação alegórica do texto escrito, além de eleger imagens capazes de produzir uma ressignificação poética da obra que está sendo lida. (SILVA, L. et al., 2009).

Em síntese, uma biblioteca escolar, para ser compreendida como tal, agrega algumas especificidades:

- tem uma função eminentemente educativa, pedagógica e em consonância com o Projeto Político Pedagógico da escola da qual faz parte;

- as suas ações são integradas com os professores, os pedagogos e o diretor da escola;

- os professores conhecem os livros que compõem o acervo da biblioteca escolar e o incorporam às suas práticas;

- é um espaço de convivência, de debate, de reflexão e de incentivo à leitura;

- os alunos têm acesso irrestrito ao acervo;

- o acervo é de qualidade e em quantidade suficiente para atender a demanda escolar; 
- $\quad$ o acervo é direcionado para os jovens leitores e, portanto, capaz de estimulá-los e cativá-los;

- $\quad$ estimula a autonomia dos seus usuários para que estes consigam de forma independente interagir e circular no espaço para buscar o que desejam e refletir sobre a leitura realizada;

- $\quad$ as ações de leitura e pesquisa ocorrem em um ambiente de liberdade e ludicidade;

- $\quad$ os mediadores de leitura desenvolvem ações planejadas, com vistas à formação do leitor e à interação entre as pessoas e as obras;

- $\quad$ os mediadores de leitura, pelo seu conhecimento literário e do acervo, podem num crescente ir desafiando os leitores que vão se tornando mais exigentes e proficientes em leitura.

\section{LIMITES E POSSIBILIDADES DO FAROL DO SABER PESQUISADO}

A biblioteca escolar tem especificidades porque é dominada pela instituição que a abriga e é organizada para atender os interesses da escola. A permanência dos usuários nela, o acesso ao acervo, a delimitação do que se pode ler e em que lugar da biblioteca, quando e durante quanto tempo se pode ler, de que forma os livros podem ser lidos - com os estudantes sentados, em pé, em silêncio ou em voz alta -, quanto tempo se pode ficar com o livro, essas são ações estipuladas e organizadas pela lógica e tempos escolares (SOARES, 2011). Nota-se que mesmo com uma boa estrutura física e com acervos de qualidade, e em quantidade suficientes, é"marginal o lugar da biblioteca na vida escolar. O espaço não é visto como importante, desprestígio que afeta aqueles que nele trabalham" (CADEMARTORI, 2012, p. 10). Não raramente os profissionais da educação desconhecem os livros disponíveis na biblioteca, e nem sempre os utilizam em sua prática pedagógica, sendo que a distância entre o professor e a biblioteca escolar contribui para uma separação ainda maior entre o aluno e o livro.

Boa parte dessas críticas são pertinentes ao Farol do Saber pesquisado, onde observaram-se a pouca presença dos alunos; o fechamento no período das férias escolares; o cerceamento do acesso ao acervo; a precária formação dos mediadores de leitura; instabilidade no quadro dos agentes de leitura; a frágil integração entre a biblioteca e a escola; o limitado engajamento dos agentes de leitura com a formação de leitores; o desinteresse e desconhecimento dos professores pelo acervo da biblioteca; e realização apenas esporádica de ações culturais. 
No Farol do Saber estudado o horário de permanência dos alunos era em média de 50 minutos, com frequência quinzenal. A turma, de acordo com o cronograma organizado pela equipe pedagógica administrativa da escola, era dividida entre duas professoras, sendo que uma delas acompanha metade da turma ao Farol do Saber (média de 15 alunos) e outra professora acompanhava a outra metade da turma ao laboratório de informática. Na semana seguinte, o grupo que foi ao Farol do Saber ia à informática e viceversa. Na semana em que havia a ação cultural, a turma toda era levada para a hora do conto no Farol do Saber e, nesse dia, não ocorriam os empréstimos. Esta organização foi acordada entre os agentes de leitura, professores e equipe pedagógica administrativa porque as turmas tinham em média 32 alunos e tanto o espaço do Farol do Saber quanto o da sala de informática não comportavam essa quantidade de crianças.

Os alunos podiam retirar dois livros para ler em casa. Percebeu-se que o momento de empréstimos oportunizava o acesso aos materiais do Farol do Saber. Demonstrou-se insuficiente o fato de os alunos só conseguirem emprestar esse material quinzenalmente ou, até mesmo, mensalmente (quando ocorria a ação cultural). É compreensível a necessidade de restringir o número de crianças no espaço reduzido do Farol do Saber, mas considerando haver agentes de leitura atendendo em período integral, poder-se-ia criar mais horários. Por exemplo, durante o recreio (quando os alunos não podem frequentá-lo) estipular-se-iam grupos que poderiam realizar empréstimos ou devoluções.

Percebeu-se também ser prejudicial à formação de leitores o fechamento do Farol do Saber no período das férias escolares, fato agravado pelo impedimento do empréstimo de livros que poderiam ser lidos nas férias. A alegação era a de que os alunos poderiam perdê-los ou não os devolver. $\mathrm{O}$ excesso de zelo pelo acervo imperava e se sobrepunha à função da biblioteca escolar, como escreve Ferreira (2009), de cativar o educando para a leitura, de democratizar o acervo, e o acesso à cultura.

Um dos problemas observados refere-se ao cerceamento do acesso ao acervo. Os agentes de leitura selecionavam previamente os livros, seguindo seus critérios de relevância e suposta adequação à faixa etária e interesses dos alunos, e os distribuíam em uma mesa. Somente estes livros podiam ser retirados pelos alunos. Contudo, a experiência do encontro espontâneo com os livros é insubstituível (PATTE, 2012) na formação de jovens leitores.

Os agentes de leitura deste Farol do Saber eram professores da Rede Municipal de Ensino de Curitiba, sendo que se alternavam os períodos em que atuavam como regentes de turma e na biblioteca escolar. Na RMBE há casos diversos, constatam-se vários professores que por estarem afastados 
da sala de aula por problemas de saúde são designados para a biblioteca escolar. Há também os de contratação por 20 horas semanais de trabalho, que se candidatam a dobrá-las para 40 horas, assumindo 20 horas na biblioteca escolar. A instabilidade no quadro de agentes de leitura prejudica muito o andamento do trabalho. Nos inícios de ano, até que os professores da escola estejam com suas turmas definidas, o Farol do Saber pode permanecer fechado aguardando a definição sobre quem serão os seus profissionais.

Agrega-se a este problema a desmotivação de bons agentes de leitura que gostariam de continuar atuando no Farol do Saber, mas são obrigados a interromper seu trabalho porque faltam professores na escola. Além no desperdício dos recursos investidos pela prefeitura na capacitação dos agentes de leitura, que acabam não permanecendo por muito tempo na biblioteca escolar, a cada mudança de pessoal cria-se a demanda de novos investimentos na sua capacitação, especialmente porque não se trata de pessoas formadas para esta atividade. W. C. Silva (2003) nos lembra que a formação do professor nos cursos de magistério e licenciatura não toma a leitura como objeto de estudo e, por esse motivo, predomina a ausência de bons projetos de formação de leitores nas escolas e, também, a fragmentação do trabalho escolar com o da biblioteca.

Durante a pesquisa foi constatado que os professores das turmas, com raras exceções, demonstravam desinteresse pelos livros disponíveis no Farol do Saber. No período em que levavam os alunos para empréstimo, nenhum professor emprestou um livro, ou sugeriu alguma obra aos seus alunos. Sua participação nesse momento limitava-se a manter a turma quieta e comportada.

Mas as limitações, às vezes, são suplantadas pelas iniciativas de algumas professoras. Uma delas, ao perceber que as visitas dos alunos ao Farol do Saber estavam limitadas às devoluções e empréstimos, proporcionava aos alunos a leitura dos livros emprestados em espaços alternativos, como o pátio ou quadra da escola. Duas professoras também liam as histórias para os alunos ou propunham uma integração com as outras turmas, onde os alunos liam uns para os outros. Durante a pesquisa esta estratégia foi observada por três vezes.

As ações culturais observadas no Farol do Saber também foram extremamente significativas, ainda que esporádicas. Notou-se que elas foram pautadas pelo desejo de compartilhar a literatura da melhor forma possível. A primeira ação cultural observada foi a leitura do livro $O$ velho, o menino e $O$ burro, fábula de La Fontaine recontada por Mônica Stahel (2013). A história foi lida por uma das agentes de leitura, enquanto a outra ia pendurando num varal cópias coloridas das ilustrações. Os grampos de madeira eram enfeitados 
com figuras dos personagens. A agente que lia a história fazia suspense, mudava o tom da voz, gesticulava, por vezes lia baixinho, lia mais alto, fazia expressões com o rosto. Lia com bastante desenvoltura demonstrando preparo para o momento. A agente de leitura parava a narrativa em alguns trechos e perguntava aos alunos:"o que vai acontecer?", e todos participavam dando ideias. Os alunos menores eram os mais entusiasmados para sugerir e inventar situações inusitadas. Após as ideias dos alunos, a agente de leitura lia a página com a ação que descrevia o que de fato aconteceu.

As crianças demonstraram concentração e bastante interesse durante a narração, mas sentiram falta de tocar no livro, sendo que quatro delas pediram para ver o livro, e a professora disse que ele ficaria no Farol do Saber para empréstimo, mas que agora não poderia emprestá-lo, pois elas deveriam voltar para suas salas. Três crianças perguntaram se só havia um exemplar no Farol do Saber, e a agente de leitura respondeu que havia dois e que na próxima semana poderiam emprestá-los. Na semana seguinte, dois desses alunos chegaram perguntando do livro.

Na segunda ação cultural observada, as agentes de leitura pediram às crianças que optassem por uma história dentre algumas pré-selecionadas, sendo uma boa oportunidade de os alunos serem ouvidos e de melhor atender os diferentes interesses. Para o Pré e $1^{\circ}$ ano leram Chapeuzinho Vermelho, de Nick Page (2014) e Branca de Neve, de Clare Fenell (2014); para os $2^{\circ}$ e $3^{\circ}$ anos Rapunzel e seu cabelo brilhante, de Gemma Cary e Kelly Caswel (2012), e Os três porquinhos, Cachinhos dourados e os três ursos, ambos de Mara Alperin (2014); para os $4^{\circ}$ anos Há um monstro embaixo da minha cama, de Clemency Pearce (2013), e O pequeno esquilo e o grande mistério, de Rachel Rivett (2011).

O planejamento foi subdimensionado e não se utilizaram os 50 minutos disponíveis, antecipando a volta às salas. Os alunos maiores chegaram a sugerir que as agentes de leitura lessem outra das histórias que estavam entre as opções, mas isto não ocorreu. Apenas disseram que, se quisessem, na semana seguinte teriam acesso para empréstimo das demais obras.

Com as turmas de $5^{\circ}$ ano foram realizadas rodas de leitura de poesia de cordel. A ação cultural iniciou com a agente de leitura lendo O imposto de honra de Leandro Gomes de Barros e, em seguida, os alunos foram convidados a tirar de um galho de árvore fitas coloridas com papeizinhos nas pontas contendo as estrofes do poema. A professora leu-o novamente, e cada aluno que pegou, por exemplo, a primeira estrofe leu também, a leitura continuou até acabarem os papéis. Os alunos acharam diferente a proposta, especialmente porque pela primeira vez puderam não apenas ouvir, mas também ler. 
A terceira ação cultural foi um pedido da diretora da escola, e foi integrada às demais comemorações organizadas para as festividades do dia da criança. Com a colaboração das professoras da escola, da diretora e das agentes de leitura, o Farol do Saber foi decorado como se fosse uma floresta. Bichos de pelúcia que foram deixados nas prateleiras, no chão e perto dos livros, juntamente com folhas secas e galhos de árvores espalhados nas escadas, além de flores de papel e outros materiais compuseram a arrumação. As crianças, ao chegarem ao Farol do Saber, eram surpreendidas com uma cortina de fitas coloridas que cobria a porta e pelo som de um CD de canto de pássaros, pela decoração alusiva à história João e Maria, fantoches com seus personagens e uma gaiola. Este objeto promoveu uma interessante integração com a escola, pois depois da ação cultural as crianças foram avisadas que a gaiola da bruxa havia sido deixada na escola para abrigar os livros que estariam disponíveis nos horários de recreio.

Quando as crianças se acomodaram no tapete do piso superior do Farol do Saber, uma das agentes de leitura leu a história João e Maria e a outra foi movimentando os fantoches das personagens. Ao final, as agentes de leitura mostraram cinco livros com versões diferentes e disseram que eles estariam disponíveis para empréstimo. A transformação do ambiente do Farol do Saber chamou muito a atenção de todos os alunos, o que não ocorreu com a contação da história, dado que a versão escolhida era demasiadamente simplista e reduzida.

Figura 2: Ação cultural 3.

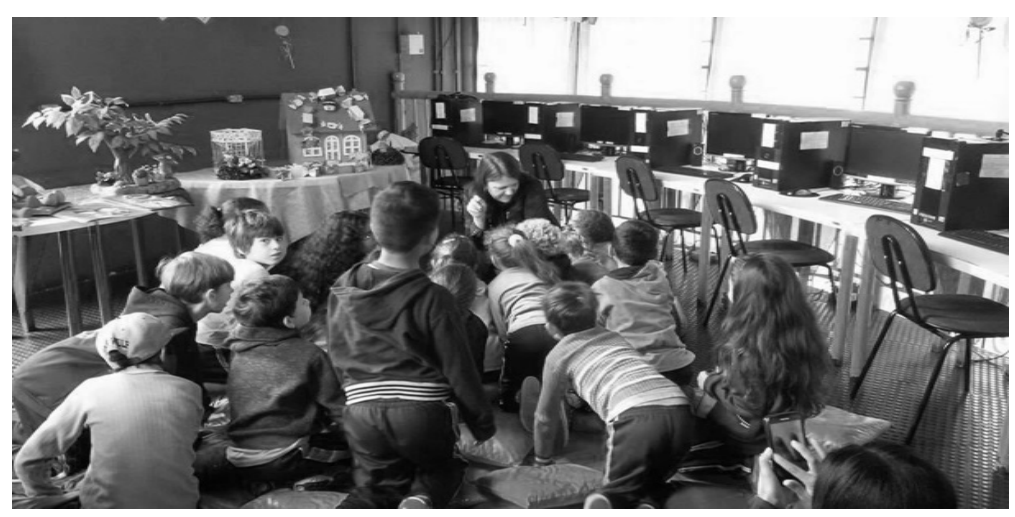

Fonte: Fotos elaboradas por uma das pesquisadoras (2015).

Outra ação cultural observada ocorreu nas turmas de $4^{\circ}$ e $5^{\circ}$ anos. Foi lido, pela agente de leitura, o livro O gato massamê e aquilo que ele vê, 
de Ana Maria Machado (2012). Eles prestaram bastante atenção, pois não conheciam a história. Depois, os alunos foram convidados a realizar a leitura em voz alta, cada um de uma parte do livro. Após, a agente de leitura sugeriu que eles recontassem a história, esperando a sua vez de falar e respeitando a vez do colega. Os alunos do $4^{\circ}$ ano foram muito participativos, porém econômicos na recuperação de detalhes da história; enquanto que apenas dois dos alunos do $5^{\circ}$ ano se pronunciaram, mas com grande riqueza de detalhes do enredo da narrativa. Ao final, os dois alunos estavam ofegantes, pois falaram rápido, e ao dizerem fim, quase juntos, foram aplaudidos pelos demais, que caíram na gargalhada.

Com as turmas dos menores foi realizada a contação da história $O$ gato xadrez de Bia Villela (2009), que foi contada com os fantoches de palito dos gatos em E.V.A coloridos. As crianças ouviram bastante entusiasmadas e empolgadas, vibrando a cada gato de cor nova que aparecia, bem como com a sonoridade provocada pelas rimas. No final, a agente de leitura distribuiu um pedaço de papel sulfite para cada criança, explicou que fariam a dobradura de um gato, e que, ao chegarem na sala de aula, pintariam da cor que achassem mais bonita, e que depois a trariam para enfeitar o Farol do Saber. As agentes de leitura revelaram em entrevista que, por considerarem a experiência de contação de história uma atividade de fruição estética, não realizavam atividades de arte ou língua portuguesa relacionadas à temática da história, com exceção desse dia.

Observou-se que as iniciativas nas ações culturais, quando adequadamente planejadas, tiveram grande potencial para que os alunos se aproximassem dos livros e que passassem a perceber o Farol do Saber como um centro de referência (SOUZA, 2009), de compartilhamento de leituras, de vivência de momentos autênticos de cumplicidade entre adultos e crianças, de valor inestimável ao cotidiano infantil (PATTE, 2012). Para Perrotti (1990, p. 72) essas atividades de leitura que utilizam as técnicas de animação cultural são um contraponto às demais atividades que apresentam a literatura de maneira negativa e que contribuem para o desinteresse do pretenso leitor. Também funcionam como difusoras da imagem da leitura como fonte de prazer já que provocam estímulos agradáveis aos partícipes.

W. C. Silva (2003) assevera ser preciso que o agente de leitura pare de reclamar que o aluno e o professor não vão à biblioteca e que ela está esquecida. $O$ autor entende ser imprescindível que a biblioteca assuma uma postura mais agressiva e desenvolva mecanismos que atraiam o professor e o aluno até o local. Não se observou nenhuma outra atividade, senão as ações culturais, que aproximasse mais os alunos, os livros, os agentes de leitura, 
os professores e o Farol do Saber. Entretanto, salienta-se a necessidade de que elas sejam corriqueiras, constantes, instigantes e impulsionadoras da formação de leitores cada vez mais autônomos e desejosos por ler.

\section{CONSIDERAÇÕES FINAIS}

Formar leitores no Farol do Saber requer um posicionamento pedagógico conjunto e aliado ao projeto político pedagógico da escola. Ainda que o Farol do Saber esteja fisicamente tão próximo da escola e que o seu potencial para formar leitores seja evidente, uma maior sinergia entre estas instituições ainda está por ocorrer.

$\mathrm{O}$ agente de leitura e o professor precisam compartilhar e refletir em conjunto, construindo relações em que as "palavras como parceria, colaboração e trabalho de equipe ganham força e sentido." (PATTE, 2012, p. 319). As oportunidades de reflexão colaborativa, entre os professores e os agentes de leitura, em torno dos livros e de uma "vontade de criar e manter condições que permitam que a leitura seja plenamente vivida" (PATTE, 2012, p. 310), podem vir a transformar o Farol do Saber num "campo profícuo para o desenvolvimento de práticas de incentivo à leitura, como lócus privilegiado para a formação de leitores literários e um núcleo ligado ao esforço pedagógico dos professores." (MORAIS, 2012, p. 39).

O Farol do Saber cumpriu sua função como biblioteca escolar nos momentos em que foi vivenciado pelos alunos como local de leitura, de convivência, de liberdade, de debate, de reflexão e ludicidade. Potencial que pode ser incrementado com a ampliação dos horários de atendimento e de permanência dos alunos; com o estímulo à autonomia dos jovens leitores para que consigam de forma independente interagir, circular no espaço e buscar o que desejam ler; com o refinamento das ações culturais para que possam atender aos interesses de leitura dos alunos e propiciar interação entre os leitores e a reflexão sobre leituras realizadas.

O redimensionamento do Farol do Saber e das suas práticas de mediação de leitura pode conduzi-lo para que de fato seja o eixo central na formação do leitor na escola. 
FAROL DO SABER: LIMITS AND POSSIBILITIES OF A SCHOOL LIBRARY IN LITERARY READER FORMATION

ABSTRACT: An ethnographic case study was developed in 2015 in order to evaluate the activities of a Farol do Saber (Knowledge Lighthouse), one of the school library units of the city of Curitiba, Brazil. The specificities of a typical school library as recommended by several authors include: adequacy to teaching and integration to school; area for interaction, debate, reflexive thinking and stimulation to reading; quality collection, adequate to young readers and thoroughly available to students and teachers; a space for freedom and play; mediators with planned actions for interaction between people and reading materials; and the fostering of autonomous readers, able to search the desired subject and think over the reading materials. In conclusion, the chosen Farol do Saber achieves some of the specificities of a school library, but must be reassessed to form readers.

KEYWORDS: School library. Reader mediator. Reader formation. Children's literature.

FAROL DO SABER: LÍMITES Y POSIBILIDADES DE UNA BIBLIOTECA ESCOLAR EN LA FORMACIÓN DE LECTORES LITERARIOS

REsUmen: En este estudio de caso de naturaleza etnográfica, desarrollado en 2015, se investigan las acciones desarrolladas en un Farol do Saber, de la administración Municipal de Bibliotecas Escolares de Curitiba. Las especificidades de una biblioteca escolar, según diversos autores, incluyen función educativa e integración a la escuela; espacio de convivencia, debate, reflexión e incentivo a la lectura; acervo de calidad, dirigido a jóvenes lectores y acceso integral y libre para alumnos y profesores; ambiente de libertad y ludicidad; mediadores de lectura con acciones planificadas para la interacción entre las personas y las obras y; fomento de lectores autónomos, capaces de buscar lo que desean en el acervo y aptos para reflexionar sobre la lectura realizada. Se concluye que el Farol do Saber investigado cumple la función de biblioteca escolar de forma limitada y necesita ser repensado para de hecho formar lectores.

PalabRas Clave: Biblioteca escolar. Mediación de lectura. Formación de lectores. Literatura infantil.

NotA

1 Trabalho completo disponível em: <http://www.prppg.ufpr.br/siga/visitante/trabal hoConclusaoWS?idpessoal=29319\&idprograma=40001016080P7\&anobase $=2016 \& \mathrm{i}$ dtc $=5>$. Acesso em: 23 maio 2018. 


\section{REFERÊNCIAS}

ALPERIN, M. Os três porquinhos. Jandira, São Paulo: Ciranda Cultural, 2014. (Coleção Primeiros Clássicos).

. Cachinhos dourados e os três ursos. Jandira, São Paulo: Ciranda Cultural, 2014. (Coleção Primeiros Clássicos).

ANDRÉ, M. E. D. A. Estudo de caso em pesquisa e avaliação educacional. Brasília: Líber Livro Editora, 2008.

ARENA, D. B. Leitura no espaço da biblioteca escolar. In: SOUZA, R. J. de (Org.). Biblioteca escolar e práticas educativas: o mediador em formação. Campinas, São Paulo: Mercado de Letras, 2009. p. 157-185.

BORTOLIN, S.; JÚNIOR, O. Bibliotecário: um essencial mediador de leitura. In: SOUZA, R. J. de (Org.). Biblioteca escolar e práticas educativas: o mediador em formação. Campinas, São Paulo: Mercado de Letras, 2009. p. 205-218.

BRASIL. Ministério da Educação. Secretaria de Educação Básica. Coordenação Geral de Materiais didáticos. Programa Nacional Biblioteca da Escola (PNBE): leitura e biblioteca nas escolas públicas brasileiras. Brasília: MEC, 2008. [elaboração de Andréa Berenblum e Jane Paiva].

CADEMARTORI, L. Somente distribuir não basta. In: PAIVA, A. (Org.) Literatura fora da caixa. O PNBE na escola: distribuição, circulação e leitura. São Paulo: Editora UNESP, 2012. p. 9-12.

CARY, G.; CASWEL, K. Rapunzel e seu cabelo brilhante. Jandira, São Paulo: Ciranda Cultural, 2012.

FENELL, C. Branca de Neve. Jandira, São Paulo: Ciranda Cultural, 2014. (Coleção Contos Clássicos Recortados).

FERREIRA, E. A leitura dialógica como elemento de articulação no interior de uma biblioteca vivida. In: SOUZA, R. J. de (Org.). Biblioteca escolar e práticas educativas: o mediador em formação. Campinas, São Paulo: Mercado de Letras, 2009. p. 69-96.

GIROTTO, C.; SOUZA, R. J. de. A Hora do Conto na biblioteca escolar: o diálogo entre a leitura literária e outras linguagens. In: SOUZA, R. J. de (Org.). Biblioteca escolar e práticas educativas: o mediador em formação. Campinas, São Paulo: Mercado de Letras, 2009. p. 19-47.

GODOY, A. Introdução à pesquisa qualitativa e suas possibilidades. Revista de Administração de Empresas, São Paulo, v. 35, n. 2, p. 57-63, mar./abr. 1995.

LÜDKE, M.; ANDRÉ, M. E. D. A. de. Pesquisa em educação: abordagens qualitativas. São Paulo: EPU, 1986.

MACHADO, A. M. O gato massamê e aquilo que ele vê. São Paulo: Ática, 2012. 
MORAIS, E. M. da C. Formam-se leitores nas bibliotecas escolares? In: PAIVA, A. (Org.). Literatura fora da caixa: o PNBE na escola: Distribuição, circulação e leitura. São Paulo: Editora UNESP, 2012. p. 36-76.

PAGE, N. Chapeuzinho Vermelho. Jandira; São Paulo: Ciranda Cultural, 2014. (Coleção Contos Clássicos Recortados).

PATTE, G. Deixem que leiam. Tradução de Leny Werneck. Rio de Janeiro: Rocco, 2012.

PEARCE, C. Há um monstro embaixo da minha cama. Jandira; São Paulo: Ciranda Cultural, 2013.

PETIT, M. Os jovens e a leitura: uma nova perspectiva. Tradução de Celina Olga de Souza. São Paulo: Editora 34, 2008.

PERROTTI, E. Confinamento cultural, infância e leitura. São Paulo: Summus, 1990.

RIVETT, R. O pequeno esquilo e o grande mistério. Jandira; São Paulo: Ciranda Cultural, 2011.

SANTOS, C.; SOUZA, R. J. de. Programas de leitura na biblioteca escolar: a literatura a serviço da formação de leitores. In: SOUZA, R. J. de (Org.). Biblioteca escolar e práticas educativas: o mediador em formação. Campinas; São Paulo: Mercado de Letras, 2009. p. 97-114.

SILVA, W. C. da. Miséria da biblioteca escolar. São Paulo: Cortez, 2003.

SILVA, L. L. M. da; FERREIRA, N. S. de A.; SCORSI, R. de Â. Formar leitores: desafios da sala de aula e da biblioteca escolar. In: SOUZA, R. J. de (Org.). Biblioteca escolar e práticas educativas: o mediador em formação. Campinas, São Paulo: Mercado de Letras, 2009. p. 49-67

SOARES, M. A escolarização da literatura infantil e juvenil. In: EVANGELISTA, A. A. M.; BRANDÃO, H. M. B.; MACHADO, M.Z. V. (Org.). A escolarização da leitura literária: o jogo do livro infantil e juvenil. 2. ed. Belo Horizonte: Autêntica, 2011. p. 17-48.

SOUZA, R. J. de (Org.). Biblioteca escolar e práticas educativas: o mediador em formação. Campinas, São Paulo: Mercado de Letras, 2009.

STAHEL, M. O velho, o menino e o burro. Fábula de La Fontaine. Bela Vista, São Paulo: Martins Fontes, 2013.

[UNESCO; IFLA] Organização das Nações Unidas para a Educação, Ciência e Cultura. Federação Internacional das Associações e Instituições Bibliotecárias. Manifesto da IFLA/UNESCO para Biblioteca Escolar. 2009. Disponível em: <http://archive.ifla.org/VII/ s11/pubs/portuguese-brazil.pdf> Acesso em: 10 abr. 2016.

VILLELA, B. O gato xadrez. São Paulo: Escala Educacional, 2009. 
Elisa Maria Dalla-Bona: Doutora em Educação pela Universidade Federal do Paraná (UFPR). Professora Adjunta do Departamento de Teoria e Prática de Ensino, Setor de Educação da UFPR. Professora do Programa de Pós-Graduação em Educação: Teoria e Prática de Ensino, da UFPR. Pesquisadora na área do letramento literário; leitura e escrita literária nos anos iniciais e finais da educação básica. Realizou, em 2010, estágio no Institut National de Rechèrche Pedagogique - INRP, em Lyon (França).

E-mail: elisabona2@smail.com

Charlene da Silva Andrade de Lima: Mestre em Educação pela Universidade Federal do Paraná (2016). Especialização em Políticas Educacionais pela Universidade Federal do Paraná (2014). Graduação em Letras Português pela Universidade Federal do Paraná (2014). Graduação em Teologia pela Faculdade Evangélica do Paraná (2008). Graduação em Pedagogia pela Universidade Federal do Paraná (2007). Profissional do Magistério e Suporte Técnico Pedagógico, ambos na Prefeitura Municipal de Curitiba. Tutora do Curso de Pedagogia EaD da Universidade Federal do Paraná.

E-mail: cd.andrdade@bol.com.br 